\title{
CREEP CHARACTERISTICS OF CONCRETE USED IN LONG-SPAN ARCH BRIDGE
}

\author{
YONGBAO WANG ${ }^{1 *}$, RENDA ZHAO $^{2}$, YI JIA², PING LIAO² \\ ${ }^{1}$ College of Architecture and Civil Engineering, \\ Taiyuan University of Technology, Taiyuan, P.R. China \\ ${ }^{2}$ School of Civil Engineering, Southwest Jiaotong University, \\ Chengdu, P.R. China
}

Received 20 September 2017; accepted 20 July 2018

\begin{abstract}
The reinforced concrete arch bridge with concrete-filled steel tubular stiffened skeleton is extensively used in the mountainous area of southwest China due to their long span and high stability. Beibanjiang Bridge located in ShanghaiKunming high-speed railway, which had a record span of $445 \mathrm{~m}$, has recently been completed in 2016. However, concrete creep and shrinkage have pronounced effects on the long-term deflection and stress redistribution of this bridge. Several concrete creep and shrinkage specimens in the natural environment were made to predict the long-term behaviour of this bridge accurately. They were used to measure the concrete creep and shrinkage of the core concrete and surrounding concrete used in the arch bridge. The test results were compared to ACI209 R-92 Prediction of Creep, Shrinkage and Temperature Effects in Concrete Structures model, 1990 CEB-FIP Model Code 1990: Design Code model, fib Model Code for Concrete Structures 2010 model and Creep and Shrinkage Prediction Model for Analysis and Design of Concrete Structures-Model B3. Based on the numerical fitting method, the fib Model Code for Concrete Structures 2010 model was modified to suit the concrete creep and shrinkage experimental results. Then, the modified fib Model Code for Concrete Structures 2010 model was used to predict the timedependent behaviour of a concrete arch bridge.
\end{abstract}

Keywords: concrete arch bridge, creep, experiment, model, shrinkage, timedependent behaviour.

* Corresponding author. E-mail: yonbaowang@163.com

Copyright $(C) 2019$ The Author(s). Published by RTU Press

This is an Open Access article distributed under the terms of the Creative Commons Attribution License (http://creativecommons.org/licenses/by/4.0/), which permits unrestricted use,

distribution, and reproduction in any medium, provided the original author and source are credited. 


\section{Introduction}

Concrete arch bridge with Concrete-Filled Steel Tubular (CFST) stiffened skeleton is a type of composite bridge possessing the high bearing capacity and ductility and has been put into practice in the southwest area of China in recent year (Xie, 2012). Beipanjiang Bridge is one of the largest concrete arch bridges located in Shanghai-Kunming Passenger Dedicated Lines (Wang, Zhan, \& Zhao, 2016). Its arch span is $445 \mathrm{~m}$, and height is $100 \mathrm{~m}$. The design speed is $350 \mathrm{~km} / \mathrm{h}$. The shape of the arch curve must be strictly controlled in service life to ensure the safety of the train operation (Bažant, Hubler, \& Yu, 2011; Bažant, Yu, \& Li, 2012a). It is known that concrete creep and shrinkage is one of the main reasons causing the long-term deformation of the arch bridge before and after the construction stages. The stress redistribution and long-term deformation of this bridge are complex and different from the Concrete-Filled Steel Tubular arch bridge (Wang, Ma, Han, \& Deng, 2013) or pre-stressed reinforced concrete bridge (Bažant, Yu, \& Li, 2012a; 2012b). Therefore, it is necessary to investigate the long-term behaviour of this bridge by experimental and theoretical methods. Figure 1 shows the overview of Beipanjiang Bridge, which was accomplished in September 2016.

At present, there are many concrete creep and shrinkage models proposed by researchers, such as ACI209 R-92 Prediction of Creep, Shrinkage and Temperature Effects in Concrete Structures model (herein ACI209 model) (ACI209 R-92, 1992), CEB-FIP Model Code 1990: Design Code model (herein CEB90 model) (CEB, 1993), Creep and Shrinkage Prediction Model for Analysis and Design of Concrete Structures-Model B3 (herein B3 model) (Bažant \& Murphy, 1995), were used to predict the long-term behaviour of concrete. However, each model has its specific condition to prevail.

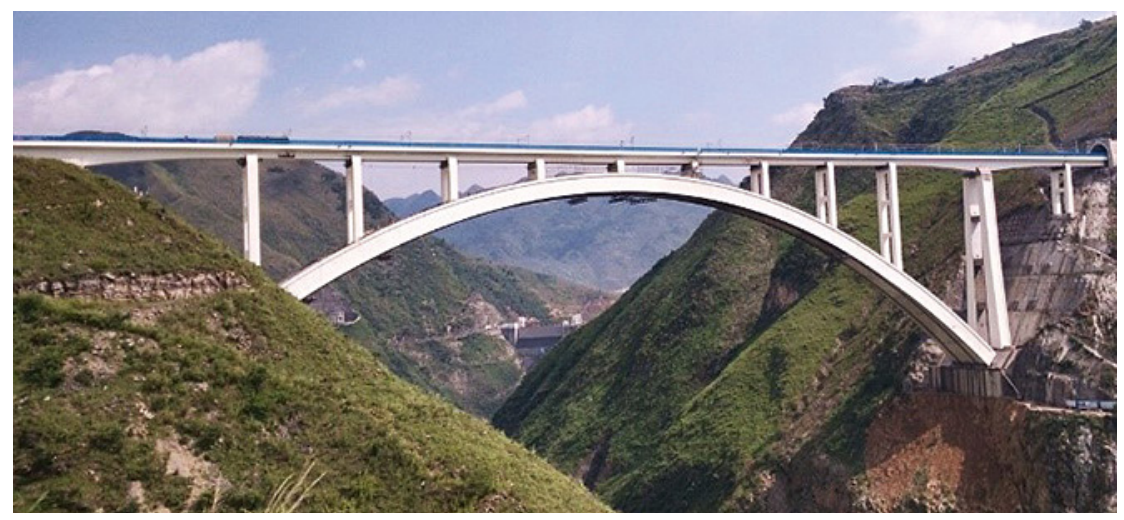

Figure 1. Overview of Beipanjiang Bridge
Creep

Characteristics of Concrete Used in Long-Span Arch Bridge 
Moreover, all model is not suitable for all the test results (Han, Xie, Zhang, \& Ma, 2016). Based on the contrastive study reported in the literature, the existing model is unreliable to estimate the creep strains of high strength concrete. Therefore, the fib Model Code for Concrete Structures 2010 model (herein CEB10 model) (CEB, 2012) and B4 model (Bažant, Jirásek, Hubler, \& Carol, 2014) was developed to appropriate for high strength concrete. Both the based models and updated models are all helpful to predict the long-term behaviour of a concrete bridge. Because the concrete bridges are exposed in the open air and suffered from rain and sunlight in all the service life, the creep strains of concrete stored in labs are different from that in environmental conditions (Gasch, Malm, \& Ansell, 2016). The multi-decade in situ measurements is used to revise the databases of laboratory test (Wendner, Tong, Strauss, \& Yu, 2015). An experimental study is an effective way to know what the concrete creep curve is. Based on partly experimental results in several months, the long-term creep coefficients in several years were obtained. Therefore, the finite element model was used to simulate the long-time behaviour of the arch bridge. At present, several researchers have studied the time-dependent behaviour of the pre-stressed concrete bridge (Bažant, Hubler, \& Yu, 2011; Bažant, Yu, and Li, 2012; Zhang, 2015; Hedegaard, French, \& Shield, 2016; Wendner, Tong, Strauss, \& Yu, 2015) and CFST bridge (Wang, Ma, Han, \& Deng, 2013; Yang, Cai, \& Chen, 2015) by finite element models. Also, the Beipanjiang Bridge was investigated by theoretical analysis (Ma, Xiang, Zhao, Xu, \& Xie, 2012; Xie, 2012). However, all researchers have never studied the long-term behaviour of this bridge based on the experimental results of concrete.

The present study aims to predict the long-term deformation of Beipanjiang Bridge. An experimental study was made in this paper to determine the concrete creep and shrinkage model. Then the comparisons were made between the test result and prediction models. These studies will enunciate some help for structural analysis and design of Beipanjiang Bridge.

\section{Concrete creep and shrinkage experimental study}

\subsection{Materials and concrete mixture}

In this experimental study, two series of concrete named C60 and C80 were used. Table 1 gives the concrete mixtures of C60 and C80 concrete. The types of cement used in two series of concrete were 
Table 1. Concrete mix specification $\left(\mathrm{kg} / \mathrm{m}^{3}\right)$

\begin{tabular}{ccccccccc}
\hline $\begin{array}{c}\text { Concrete } \\
\text { type }\end{array}$ & Cement & Slag & $\begin{array}{c}\text { Silica } \\
\text { fume }\end{array}$ & Sand & $\begin{array}{c}\text { Coarse } \\
\text { aggregate }\end{array}$ & $\begin{array}{c}\text { Water } \\
\text { reducing } \\
\text { agent }\end{array}$ & Water $\begin{array}{c}\text { Expansion } \\
\text { agent }\end{array}$ \\
\hline C60 & 350 & 125 & 25 & 667 & 1088 & 6.0 & 145 & - \\
C80 & 406 & 87 & 41 & 670 & 1005 & 11.6 & 145 & 46 \\
\hline
\end{tabular}

Ordinary Portland cement CEM-I-42.5N/SR. The slag used in this study was used to replace part of cement. It reduces the concrete creep and shrinkage strains in some content (Bažant, Jirásek, Hubler, \& Carol, 2014).

The coarse aggregate was crushed volcanic rock. Its density is $2710 \mathrm{~kg} / \mathrm{m}^{3}$; aggregate size is $5-20 \mathrm{~mm}$ and tight porosity is $40 \%$. River sand was exploited in Yueyang, Hunan Province, whose density is $2680 \mathrm{~kg} / \mathrm{m}^{3}$ and fineness modulus is 2.6. The superplasticiser of poly hydroxyl with the content of $1.2 \%$ was used as a water-reducing admixture. It was used in C60 and C80 concrete. FK-ZY expansion agent was only used in C80 concrete to increase the bond between the steel tube and core concrete. Water was taken from Beipanjiang River.

\subsection{Concrete strength and elastic modulus}

In this study, 144 rectangular prisms with the size of $150 \times 150 \times 300 \mathrm{~mm}$ were used to test the concrete compressive strength and elastic modulus. Both of C60 and C80 concrete all have 72 specimens, and they were divided into 12 groups. In each group, three members were used to test the strength and the others were used to measure the elastic modulus. It was measured on days: $1,3,7,14,28,45,60,90,120,150,180$, and 360 .

All the specimens were placed in a natural environment near the arch bridge to reflect the concrete mechanical properties at the bridge site. When the concrete cured to the corresponding loading age, the strength and elastic modulus were tested. Air content test was carried out and slump values in the range $200-260 \mathrm{~mm}$ were determined. Table 2 presents the measured strength and the elastic modulus. As shown in Table 2, the C80 concrete has higher strength than C60 in ages. However, there is little difference in elastic modulus between C60 and C80 concrete. The concrete strength for 1 day after demolding had gained about $72 \%$ and $53 \%$ of strength at 28 days for $\mathrm{C} 60$ and C80 concrete, respectively. After 28 days, the concrete strength becomes stable. The measured strength and elastic modulus are shown in Table 2 are used in calculating the time-dependent behaviour of the concrete arch bridge. 
Table 2. Mechanical properties of concrete

\begin{tabular}{|c|c|c|c|c|}
\hline \multirow{2}{*}{$\begin{array}{l}\text { Time, } \\
\text { days }\end{array}$} & \multicolumn{2}{|c|}{$\begin{array}{c}f_{c m,} \\
\mathrm{MPa}\end{array}$} & \multicolumn{2}{|c|}{$\begin{array}{c}E_{c \prime} \\
10^{4} \mathrm{MPa}\end{array}$} \\
\hline & C60 & C80 & C60 & C80 \\
\hline 1 & 36.5 & 34.8 & 3.80 & 3.14 \\
\hline 3 & 33.3 & 51.6 & 4.26 & 3.42 \\
\hline 7 & 46.2 & 52.2 & 4.04 & 3.70 \\
\hline 14 & 49.0 & 55.0 & 4.33 & 4.21 \\
\hline 28 & 50.7 & 65.7 & 4.27 & 4.24 \\
\hline 45 & 51.9 & 62.9 & 4.71 & 4.28 \\
\hline 60 & 55.1 & 71.4 & 4.32 & 4.00 \\
\hline 90 & 52.3 & 69.3 & 4.31 & 4.52 \\
\hline 120 & 52.0 & 69.9 & 4.24 & 4.37 \\
\hline 150 & 51.5 & 74.6 & 4.77 & 4.32 \\
\hline 180 & 50.2 & 74.4 & 4.14 & 4.39 \\
\hline 360 & 55.4 & 75.2 & 4.72 & 4.45 \\
\hline
\end{tabular}

\subsection{Specimens and test set up}

In Table 3, eight groups of cylinders $(250 \times 500 \mathrm{~mm})$ named W1, W2, W3, W-S, C1, C2, C3, C-S were used to determinate the concrete creep and shrinkage properties. C60 and C80 concrete were divided into four groups. Three groups were used to test the creep strain. Moreover, one group was used to measure the shrinkage strain. In addition, each group has three members. C60 and C80 test specimens represent the surrounding concrete and core concrete, respectively. Three vibrating wire strain sensors (Wang, Zhao, Chen, Xu \& Xie, 2017) were installed in the middle part of each testing cylinder, as shown in Figure 2. These sensors were placed on vertices of an equilateral triangle. Therefore, the measured strains on the cross section are the average values of those three sensors. Both strains and temperatures were measured by the vibrating wire strain sensors used in this study.

All specimens were manufactured in steel moulds as shown in Figure 3a. After 48 hours, the moulds were removed. Moreover, specimens were all placed in the open air near the bridge, in which the temperatures and humidity were changed with time. The C80 concrete was used to simulate the concrete embedded in the steel tube. It was sealed by paraffin wax. Moreover, the sun shading formwork was arranged outside of the specimens (Figure 3d). All the specimens 
Table 3. Grouping of shrinkage and creep test members

\begin{tabular}{|c|c|c|c|c|c|c|c|c|c|}
\hline \multirow{4}{*}{ Property } & \multirow{4}{*}{ Unit } & \multicolumn{8}{|c|}{ Concrete } \\
\hline & & \multicolumn{4}{|c|}{$\mathrm{C60}$} & \multicolumn{4}{|c|}{ C80 } \\
\hline & & \multicolumn{8}{|c|}{ Group } \\
\hline & & W1 & W2 & W3 & W-S & C1 & $\mathrm{C2}$ & C3 & C-S \\
\hline Loading or Testing Age & days & 7 & 28 & 90 & 3 & 28 & 120 & 200 & 28 \\
\hline Design Stress & $\mathrm{MPa}$ & 10 & 10 & 10 & 0 & 10 & 10 & 6 & 0 \\
\hline $\begin{array}{l}\text { Measured Instantaneous } \\
\text { Strain }\end{array}$ & $\mu \varepsilon$ & 392 & 308 & 321 & - & 292 & 236 & 185 & - \\
\hline Measured Stress & $\mathrm{MPa}$ & 15.8 & 13.2 & 13.8 & - & 12.4 & 10.3 & 8.1 & - \\
\hline Stress Tolerances & $\%$ & 58 & 32 & 38 & _- & 24 & 3 & 35 & _- \\
\hline
\end{tabular}

suffered from the sunlight and rain. Therefore, the measured creep and shrinkage are more likely the bridge concrete. The general view of specimens is shown in Figure 3.

A lever loading device was established near the bridge. The main advantage of this loading device is that it ensures the external load on the concrete column as constant. However, its loading process is relatively complex than commonly used testing instrumentations such as Yang, Cai, \& Chen (2015). The details of the testing instrumentations are shown in Figure 4. Based on the force equilibrium condition, the relationship between $N$ and $G$ (Figure 4) was obtained from Eq. (1). When the designed stress applied to the concrete specimens was defined, the weight of the counterweight was calculated.

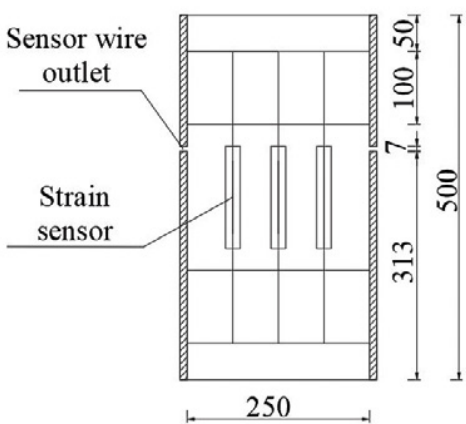

a) elevation (units in $\mathrm{mm}$ )

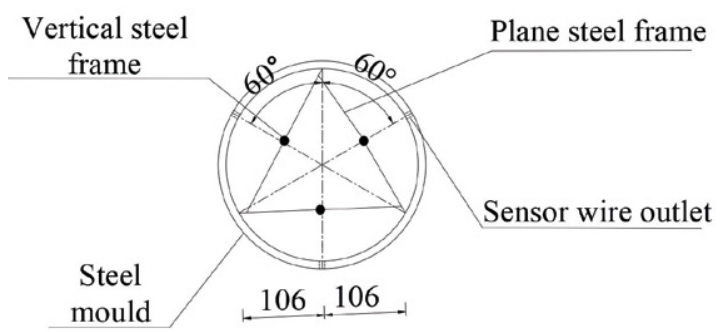

b) bross section (units in $\mathrm{mm}$ )

Figure 2. Design drawing and instrumentation layout 


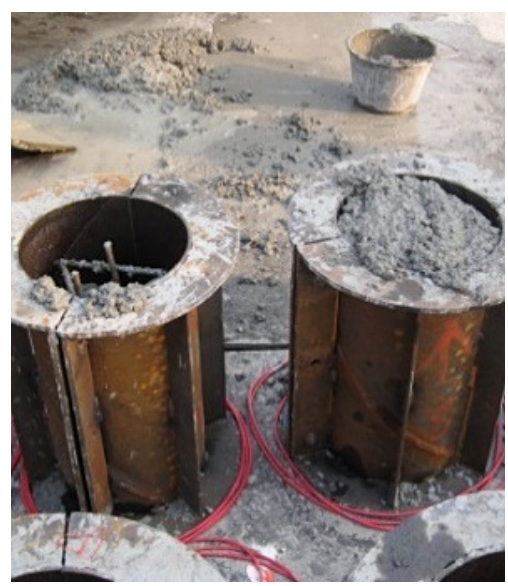

a) casting concrete

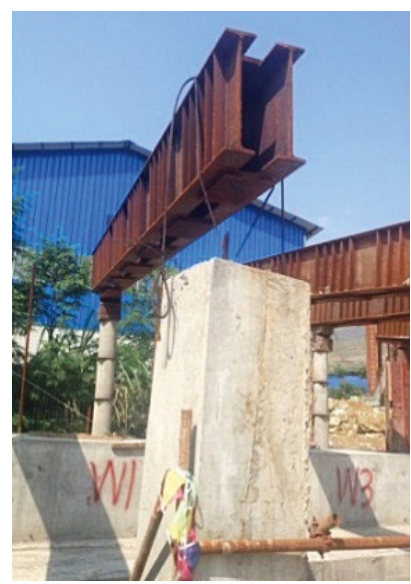

b) counterweight

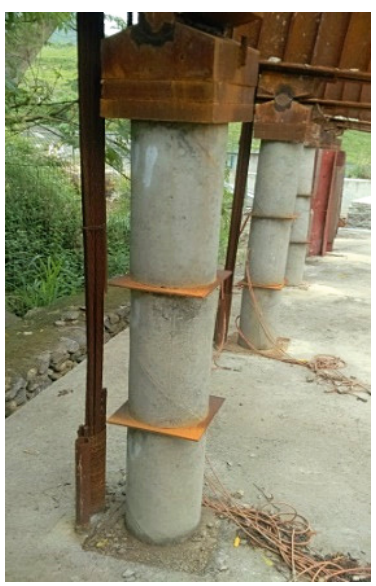

c) $\mathrm{C} 60$ creep member

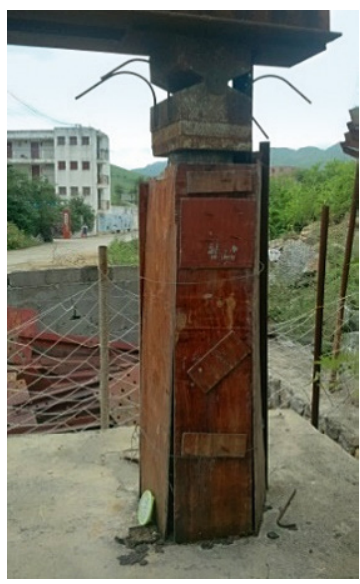

d) C80 creep member

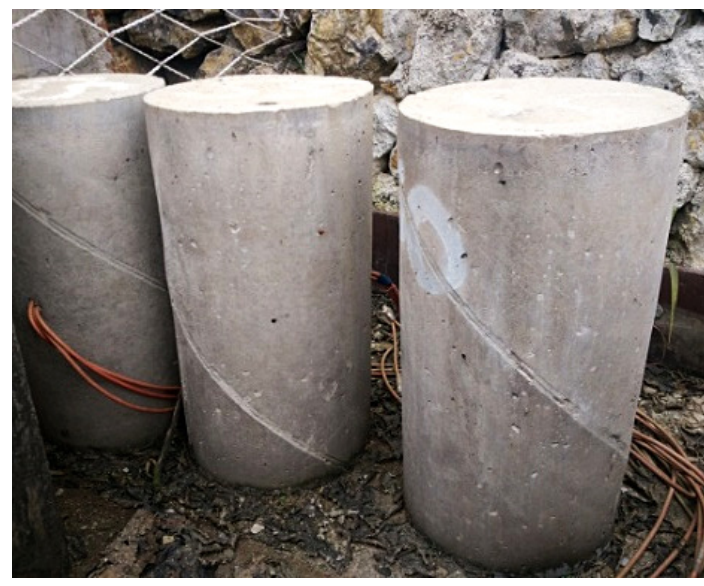

e) shrinkage member

Figure 3. General view of the experiment

$$
N=F+G=G\left(1+\frac{b}{a}\right)+\frac{1}{2} \frac{q}{a}\left(b^{2}-a^{2}\right),
$$

$a$ - the distance between the axis of steel strand and loading specimen $/ \mathrm{m} ; b$ - the distance between the axis of counterweight and loading specimen/m; $F$ - the force applied on steel strand/N; $N$ - the force applied to the specimens/N; $G$ - the dead load of counterweight/N; $q$ - represents the transformed uniformly distributed load of steel beam/ $\mathrm{N} \mathrm{m}^{-1}$. 


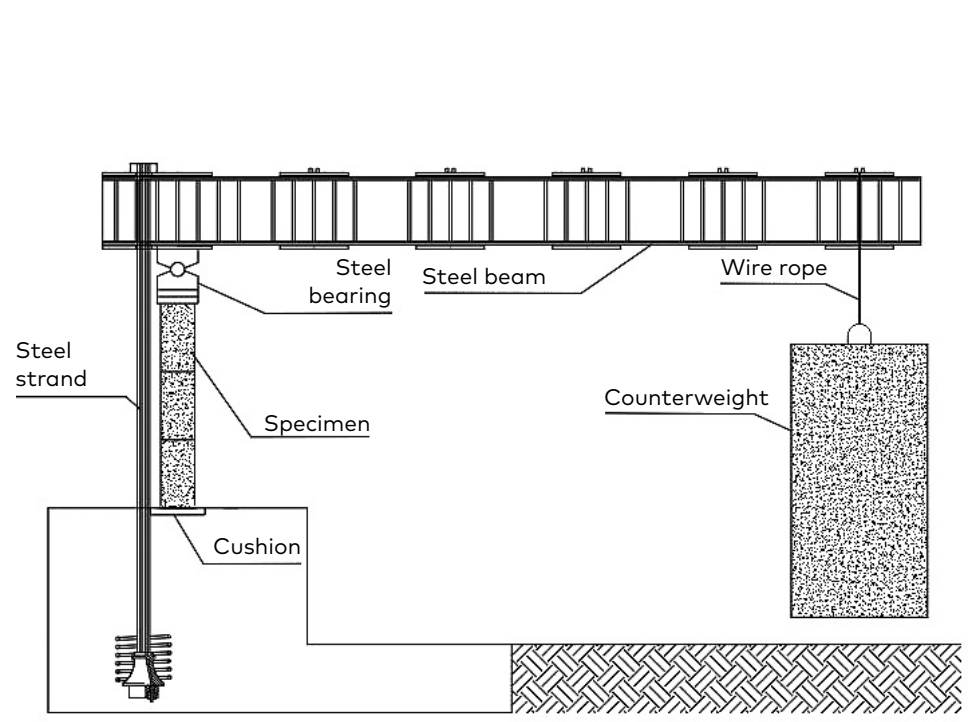

a) diagrammatic sketch

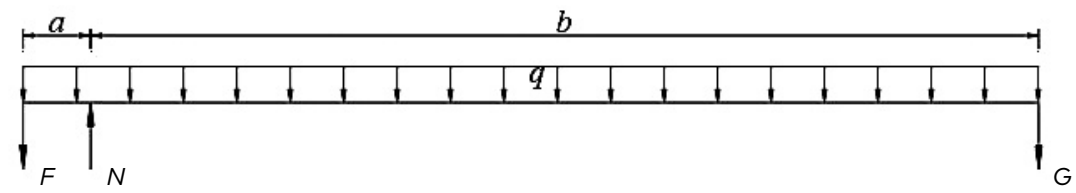

b) diagram of mechanical analysis

Figure 4. Test device

\section{Experimental results and analysis}

\subsection{Experimental results}

The measured temperatures and relative humidity in the natural environment during the long-term tests are presented in Figure 5. As shown in Figure 5, the temperature is periodically changed over time. It changed from $2{ }^{\circ} \mathrm{C}$ in winter to $40{ }^{\circ} \mathrm{C}$ in summer. However, the relative humidity in the range from $40 \%$ to $95 \%$ change with time irregularly, that phenomena were similar to Wendner, Tong, Strauss, \& Yu (2015). The average relative humidity $65.7 \%$ in Figure 5 was used for calculation in this study. It is known that the measured shrinkage and creep strains were influenced by temperatures. In this experiment, Wang, Zhao, Chen, Xu, \& Xie (2017) have already studied the temperature effects of vibrating wire strain sensor embedded in these specimens. Therefore, the measured results are modified by Eq. (2).

$$
\varepsilon_{m}=\varepsilon_{t}+A(T-20)+B
$$


where $\varepsilon_{m}$ and $\varepsilon_{t}$ - the modified and test strains, respectively, $\mu \varepsilon ; T-$ temperature, ${ }^{\circ} \mathrm{C}$; $A$ and $B$ are coefficients; for shrinkage member $A=-2.15 \mu \varepsilon^{\circ} \mathrm{C}^{-1}, B=3.16 \mu \varepsilon$; for creep member $-A=-2.54 \mu \varepsilon^{\circ} \mathrm{C}^{-1}, B=$ $6.32 \mu \varepsilon$.

The shrinkage strain curves of $\mathrm{C} 60$ and C80 are depicted in Figure 6a and Figure 7a. As shown in these Figures, the initial measurement time is 3 days and 28 days for C60 and C80 concrete, respectively. Therefore, for $\mathrm{C} 60$ concrete, the shrinkage strain increases rapidly to the ultimate strain during the first 100 days, then the average shrinkage strain becomes stable at about $140 \mu \varepsilon$. However, the shrinkage strain of C80 concrete develops much slower than C60 concrete at first 100 days. It fluctuates within 60 days to 100 days. Moreover, it develops much rapidly from 100 days to 300 days, then becomes stable. The shrinkage curves of these two batches concrete have different development tendency because of the expansion agent added in C80 concrete. The shrinkage strains of C60 concrete are greater than those of $\mathrm{C} 80$ concrete, and the ratio of the former to latter is about four times at 850 days after casting. The high strength concrete used in this bridge has less shrinkage strain than ordinary strength concrete.

Figure $6 \mathrm{~b}$ and Figure $7 \mathrm{~b}$ give the creep coefficients of two series of concrete subjected to three types of loading age. In these curves, the concrete shrinkage and temperature strains have been excluded. The instantaneous strains of series $\mathrm{W}$ and $\mathrm{C}$ are shown in Table 3. Not all measured elastic stresses matched with the design values except C2. The design loading values applied by the test device shown in Figure 4 was ensured. It is seen from Figure $6 \mathrm{~b}$ and Figure $7 \mathrm{~b}$ that,

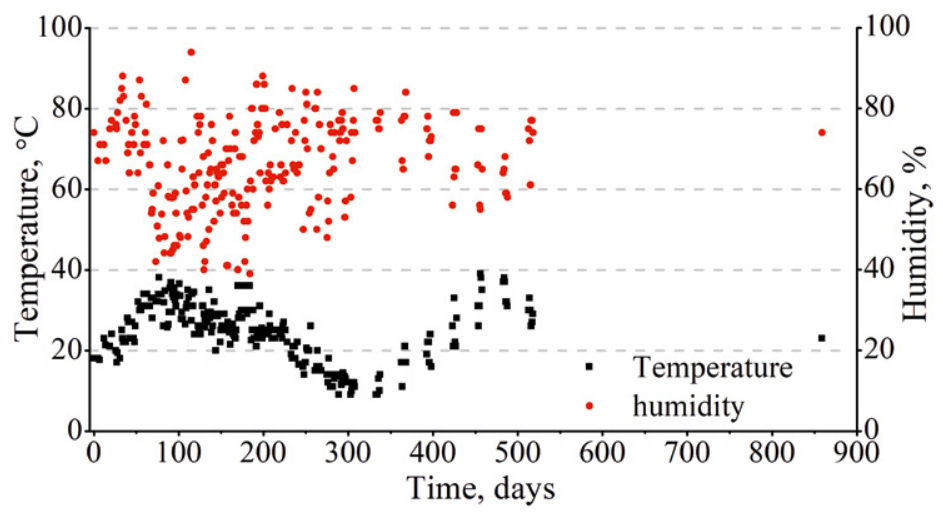

Figure 5. Temperature and relative humidity during the long-term testing 


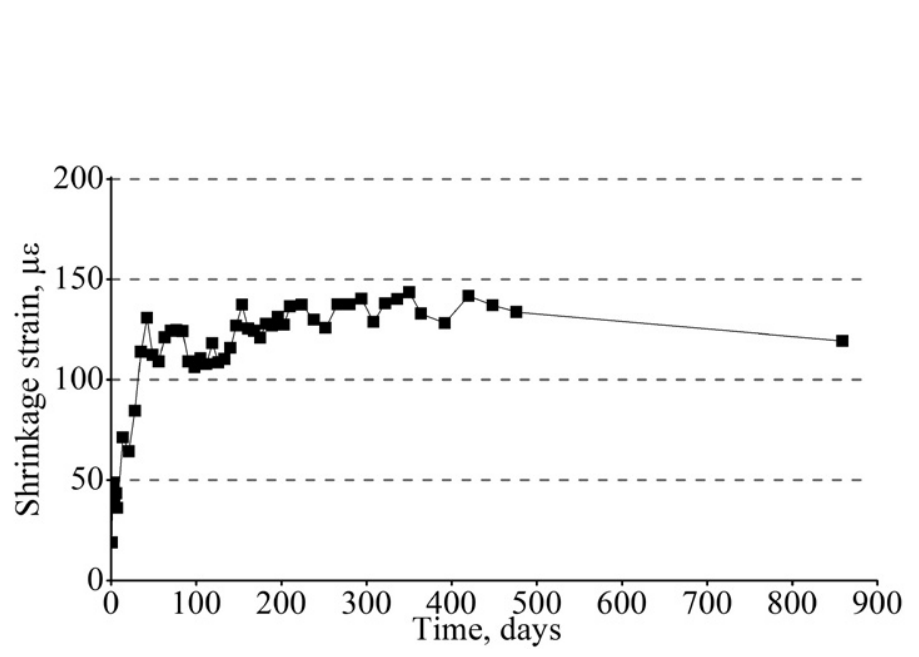

a) shrinkage strains

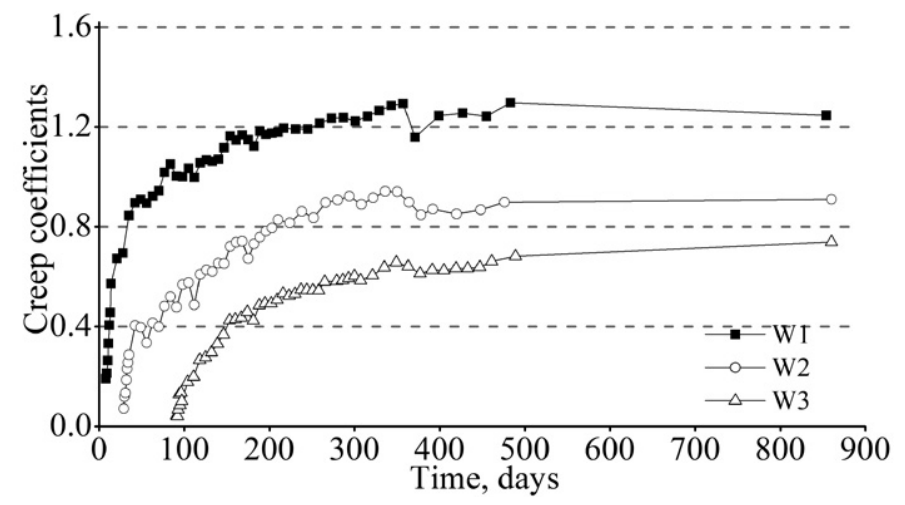

b) creep coefficients

Figure 6. Shrinkage strains and creep coefficients versus age for $\mathrm{C} 60$ concrete

no matter for $\mathrm{C} 60$ or $\mathrm{C} 80$ concrete, the creep coefficient decreases with the increase of loading age. Although both of W2 and C1 are all loaded at 28 days, W2 have larger creep coefficients than C1, because of the lower compressive strength than C1. For C80 concrete, when the loading age is longer than 120 days, it has little effect on the creep coefficients ( $\mathrm{C} 2$ and $\mathrm{C} 3$ curves in Figure $7 \mathrm{~b}$ ). It must be pointed out that after about 400 days, there is still a larger increase of creep for C80, which is familiar with the results of Yang, Cai, \& Chen (2015). By the end of 861 days, the creep coefficients ratios of the concrete load at 28 days and 90 days to the concrete loaded at 7 days are 0.7523 and 0.6458 , respectively. 


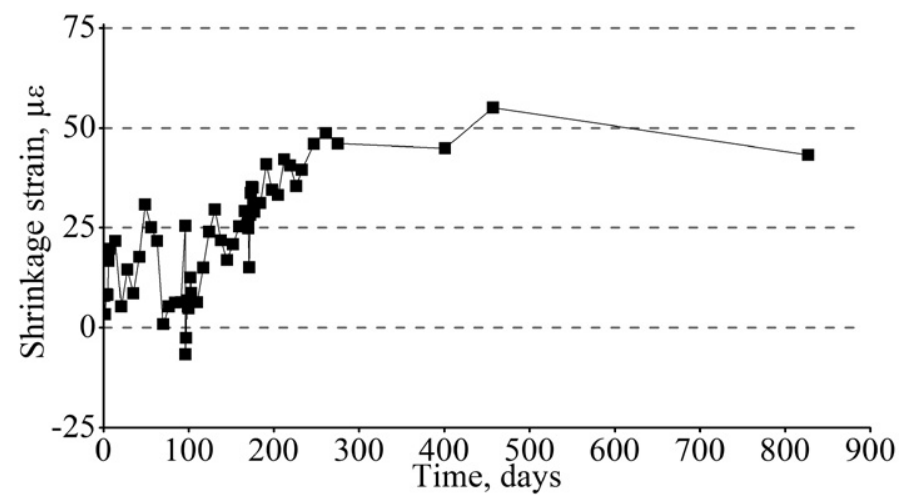

a) shrinkage strains

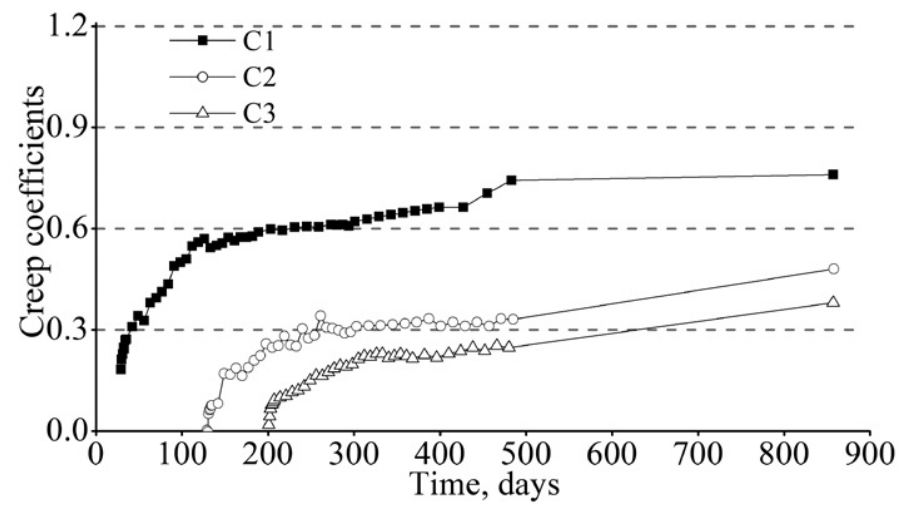

b) creep coefficients

Figure 7. Shrinkage strains and creep coefficients versus age for C80 concrete

Also, the creep and shrinkage strains of concrete stored in natural environment fluctuated with time, whose effect is different from the concrete placed in the lab environment. Because they are influenced by the temperature and relative humidity in the surrounding environment. Those phenomena are shown in Figures 6 and 7. However, the overall trend of strains is still increasing with time.

\subsection{Comparison of existing models}

The time-dependent prediction models used in this paper are ACI209 model (ACI209 R-92, 1992), CEB90 model (CEB, 1993), B3 model (Bažant \& Murphy, 1995) and CEB10 model (CEB, 2012). 
Different models need various parameters (Han, Xie, Zhang, \& Ma, 2016), such as the age of concrete at loading, mean relative humidity, the mean concrete compressive strength at 28 days. All the needed parameters used in this study are listed in Table 4 . The mean relative humidity for C60 concrete is the average value of the test results shown in Figure 4. Moreover, the mean relative humidity for C80 is assumed to $90 \%$ because the surfaces of the testing member are covered by wax (Qian 2016). Average thickness $h$ is used for all models expect ACI209 model (ACI209 R-92, 1992). Volume to surface area ratio, slump, air content and proportion of fine aggregate are only used for the ACI209 model (ACI209 R-92, 1992).

The comparisons of experimental results with calculated ones by different prediction models are shown in Figures 8 and 9. It is shown from these figures that all models overestimate the measured shrinkage strains for two series of concrete. Among those models, CEB90 model (CEB, 1993) is most closed to the experimental results. Also, the creep coefficients predicted by different models all overestimated the measured results, especially for C60 concrete. For C60 concrete, the creep obtained by ACI209 model (ACI209 R-92, 1992 ) is most closed to the test results; For C80 concrete, CEB90 model (CEB, 1993) is near to the creep coefficients with the loading age of 7 days. Moreover, CEB10 model (CEB, 2012) is more closed to the experimental results of $\mathrm{C} 2$ and $\mathrm{C} 3$ with the loading age of 120 days and 200 days, respectively. Generally, none of the available concrete shrinkage and creep models is satisfied with all the experimental results.

Table 4. Parameters used for prediction models

\begin{tabular}{|c|c|c|c|}
\hline Parameters & & $\mathrm{C} 60$ & C80 \\
\hline Age at loading & $t_{\circ}$ & $\begin{array}{l}7 \text { days, } \\
28 \text { days, } \\
90 \text { days }\end{array}$ & $\begin{array}{c}28 \text { days, } \\
120 \text { days, } \\
200 \text { days }\end{array}$ \\
\hline Mean Relative Humidity & $\mathrm{RH}$ & $65.70 \%$ & $90.00 \%$ \\
\hline Mean compressive strength at 28 days & $f_{\mathrm{cm} 28}$ & $40.6 \mathrm{MPa}$ & $52.6 \mathrm{MPa}$ \\
\hline Average thickness & $h=2 A_{c} / u$ & $127.5 \mathrm{~mm}$ & $127.5 \mathrm{~mm}$ \\
\hline Volume to surface area ratio & $V / S$ & $50.8 \mathrm{~mm}$ & $50.8 \mathrm{~mm}$ \\
\hline Slump & s & $215 \mathrm{~mm}$ & $250 \mathrm{~mm}$ \\
\hline Air content & $\alpha$ & $3.0 \%$ & $2.5 \%$ \\
\hline Proportion of fine aggregate & $\Psi_{a}$ & $42.9 \%$ & $44.3 \%$ \\
\hline
\end{tabular}




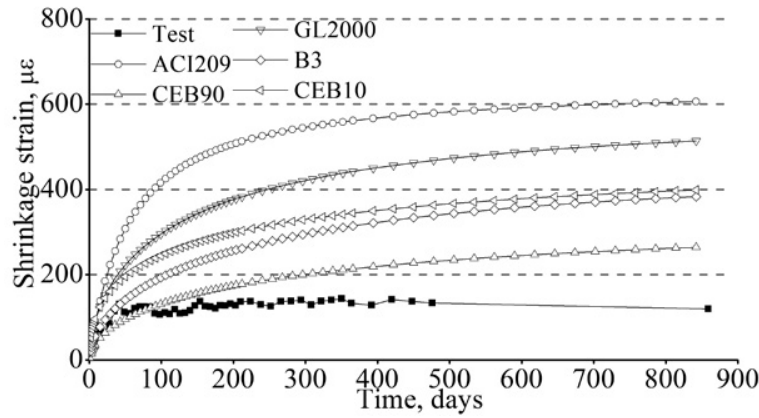

a) W-S

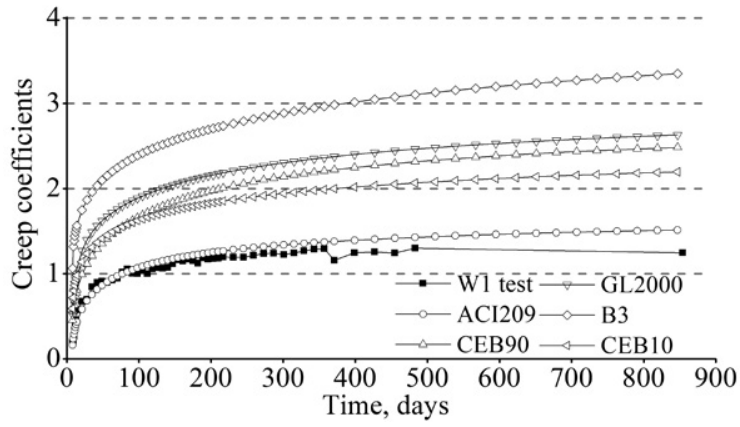

b) W1

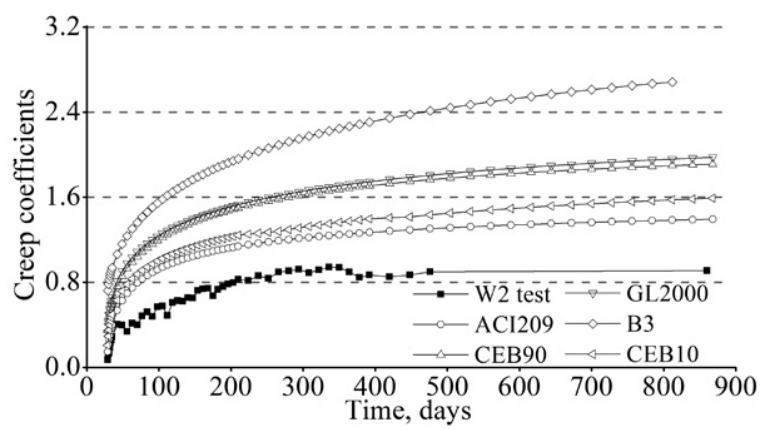

c) W2

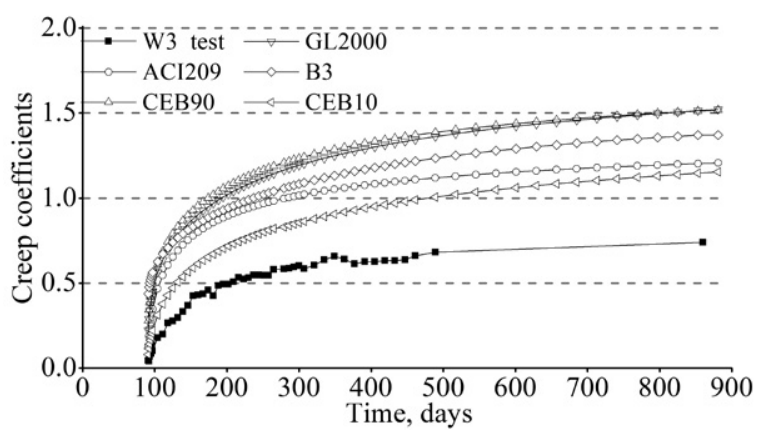

d) $W 3$

Figure 8. Comparison of experimental and predicted results for $\mathrm{C} 60$ concrete 

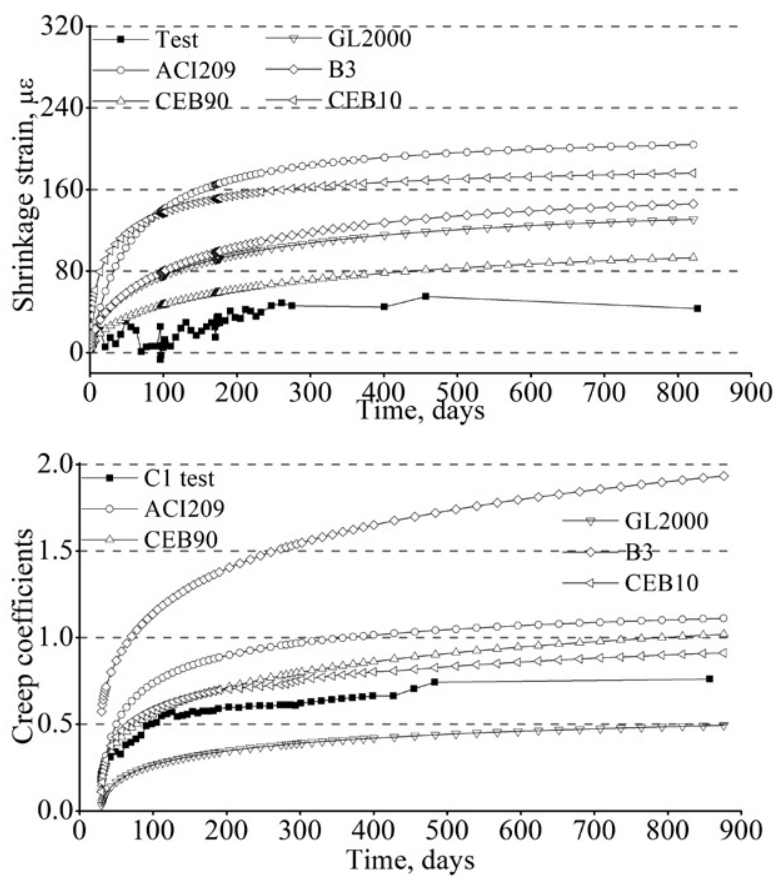

a) C-S

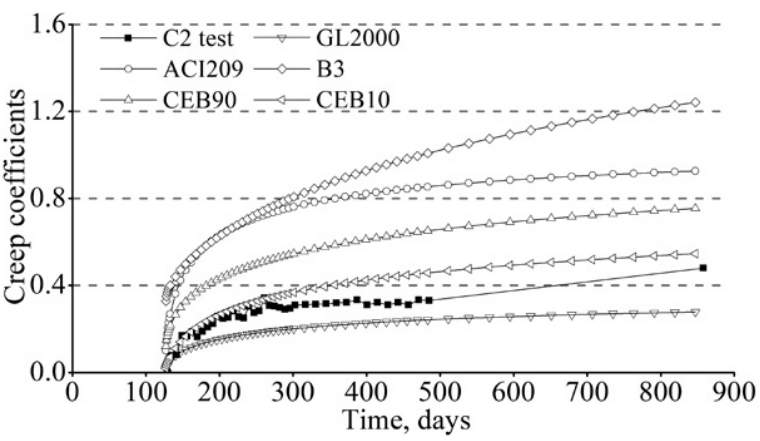

b) $\mathrm{C} 1$

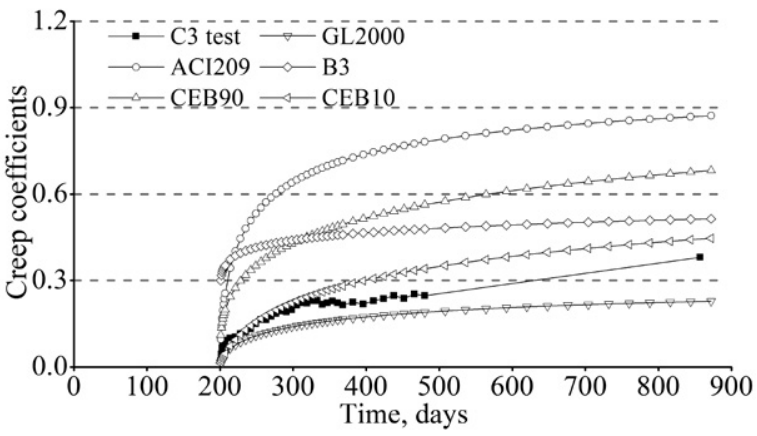

Figure 9. Comparison of experimental and predicted results for $\mathrm{C} 80$ concrete 


\subsection{Modified shrinkage and creep models}

It was seen from Figures 8 and 9 that nearly no shrinkage and creep curves obtained by the traditional models matched well with the experimental data. Compared with other models, CEB10 model (CEB, 2012) is more closed to the creep experiments results. Moreover, it is still more suitable for high strength concrete, especially for normal weight high strength concrete with a characteristic compressive strength between C60 and C100 (CEB, 2012). Thus, a modified CEB10 (CEB, 2012) shrinkage and creep model according to the experimental results by minimising the difference between the experimental results and models was needed.

Based on the experimental results and CEB10 model (CEB, 2012), the shrinkage and creep curves of $\mathrm{C} 60$, and C80 concrete were fitted. All the fitted formulas are listed in Eqs. (3) to (6). The initial testing ages of shrinkage specimens of C60 and C80 are 3 days and 28 days, respectively. The ultimate shrinkage strains of C60 are about double of C80 as shown in Eqs. (3) and (5).

Shrinkage model of C60 concrete:

$$
\varepsilon_{s h}(t)=0.46 \varepsilon_{s h C E B}(t)
$$

Creep model of C60 concrete:

$$
\varphi_{\text {СЕВ }}\left(t, t_{0}\right)=0.63 \varphi_{\text {СЕВ }}\left(t, t_{0}\right)
$$

Shrinkage model of C80 concrete:

$$
\varepsilon_{s h}(t)=0.21 \varepsilon_{s h C E B}(t)
$$

Creep model of C80 concrete:

$$
\varphi_{\mathrm{CEB}}\left(t, t_{0}\right)=0.85 \varphi_{\mathrm{CEB}}\left(t, t_{0}\right)
$$

where $\varepsilon_{\text {sh СEB }}(t)$ - shrinkage strains calculated by CEB10 model (CEB, $2012) ; \varphi_{\text {СЕВ }}\left(t, t_{0}\right)$ - creep coefficients calculated by CEB10 model (CEB, 2012).

Further, the creep coefficient curves predicted from the modified model were compared with the experimental results, as shown in Figure 10. As shown these figures that the modified CEB10 model (CEB, 2012) is more suitable to represent the creep behaviour of the test specimens. Good agreement between the results of the modified CEB10 model (CEB, 2012) and the experimental results was observed. Compared with the modified creep models, the precision of the shrinkage models are worse than the creep model. The models are shown in Eqs. (3) to (6) will be used to calculate the time-dependent behaviour of the concrete arch bridge. 

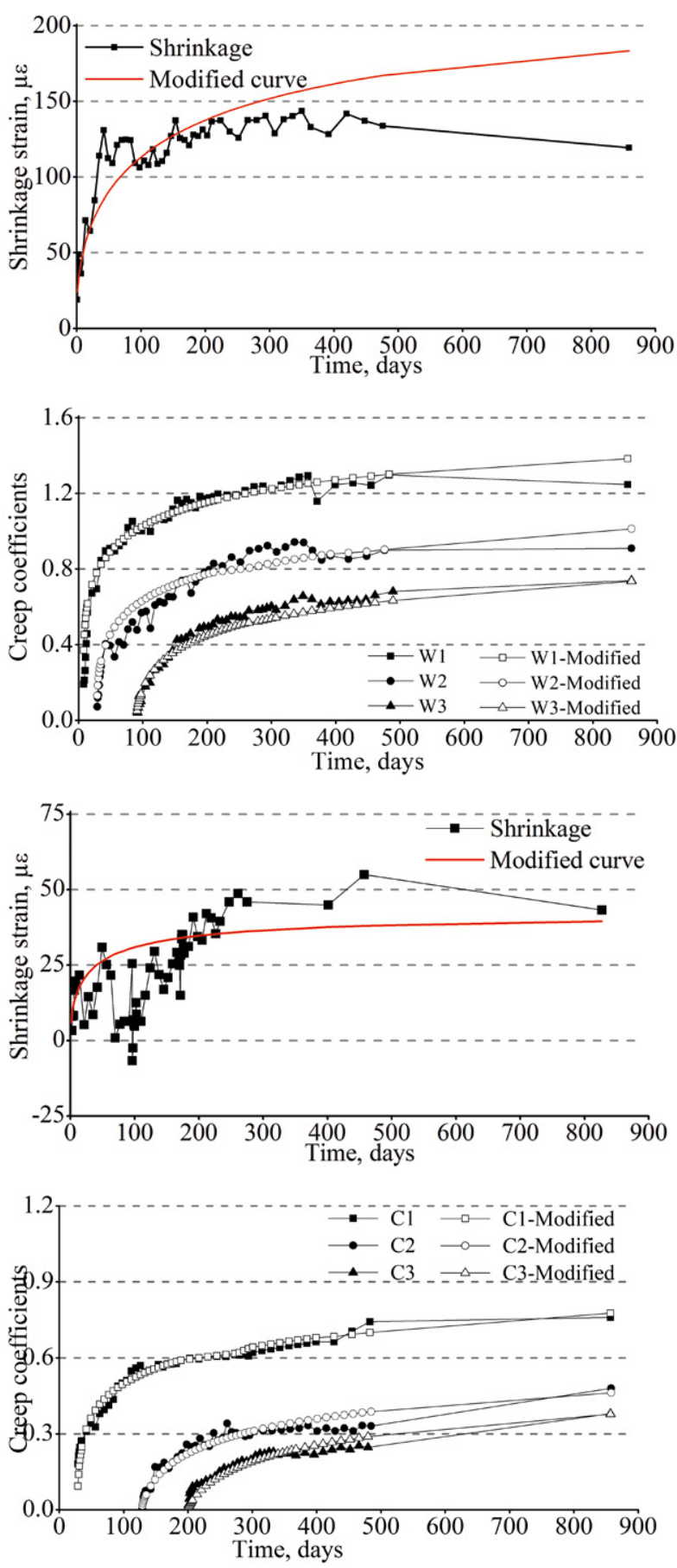

Creep

Characteristics of Concrete Used in Long-Span Arch Bridge a) shrinkage
of $\mathrm{C} 60$ concrete

b) creep of C60 concrete c) shrinkage of $\mathrm{C} 8 \mathrm{O}$ concrete

Figure 10. Predicted shrinkage and creep curves from modified models 


\section{Conclusions}

1. The shrinkage of C60 concrete increased rapidly at first 100 days after loading, then become stable. However, because of the expansion agent, the shrinkage curves of C80 concrete show negative values in the first 100 days after loading, and then increase with time from 100 days to 400 days. Ultimate shrinkage and creep strains of high strength concrete used in Beipanjiang Bridge are less than that of ordinary concrete; the shrinkage and creep strains of $\mathrm{C} 60$ concrete used in the surrounding concrete are larger than C80 concrete used in core concrete.

2. Among the commonly used models, none of the models is suitable for all the experimental results. All of which overestimate the experimental results of $\mathrm{C} 60$ concrete. The creep coefficients obtained by ACI209 R-92 Prediction of Creep, Shrinkage and Temperature Effects in Concrete Structures model are closer to the experimental results of C60 concrete; fib Model Code for Concrete Structures 2010 model gives a better prediction to the creep coefficients of C80 concrete. The available models appear to be inadequate to be used in the time-dependent behaviour analysis of Beipanjiang Bridge.

3. The correlation between the measured and those calculated by the modified fib Model Code for Concrete Structures 2010 model is significantly closer to each other. The modified fib Model Code for Concrete Structures 2010 model is suitable to be used to calculate the time-dependent response of Beipanjiang Bridge.

\section{Acknowledgements}

The experiment test in this work was sponsored by The China Railway Eryuan Engineering Group Co. Ltd.

And the support from the National Natural Science Foundation of China (Grant No. 51778531) is acknowledged.

\section{REFERENCES}

ACI209 R-92 (1992). Prediction of Creep, Shrinkage and Temperature Effects in Concrete Structures

Bažant, Z. P., Hubler, M. H., \& Yu, Q. (2011). Excessive creep deflections: An awakening. Concrete international, 33(8), 44-46. 
Bažant, Z. P., Jirásek, M., Hubler, M. H., \& Carol, I. (2015). RILEM draft recommendation: TC-242-MDC multi-decade creep and shrinkage of concrete: material model and structural analysis. Model B4 for creep, drying shrinkage and autogenous shrinkage of normal and high-strength concretes with multi-decade applicability. Materials and structures, 48(4), 753-770. https://doi.org/10.1617/s11527-014-0485-2

Bažant, Z. P., Yu, Q., \& Li, G. H. (2012a). Excessive long-time deflections of prestressed box girders. I: Record-span bridge in Palau and other paradigms. Journal of Structural Engineering, 138(6), 676-686. https://doi.org/10.1061/(asce)st.1943-541x.0000487

Bažant, Z. P., Yu, Q., \& Li, G. H. (2012b). Excessive long-time deflections of prestressed box girders. II: Numerical analysis and lessons learned. Journal of Structural Engineering, 138(6), 687-696. https://doi.org/10.1061/(ASCE)ST.1943-541X.0000375

Bažant, Z.P. \& Murphy, W. P. (1995). Creep and Shrinkage Prediction Model for Analysis and Design of Concrete Structures-Model B3. Materials and Structures 28:357-365. https://doi.org/10.1007/BF02473152

Comite Euro-International du Beton (CEB) (1993). 1990 CEB-FIP Model Code 1990: Design Code

Comite Euro-International du Beton (CEB) (2012). fib Model Code for Concrete Structures 2010

Gasch, T., Malm, R., \& Ansell, A. (2016). A coupled hygro-thermo-mechanical model for concrete subjected to variable environmental conditions. International Journal of Solids and Structures, 91, 143-156. https://doi.org/10.1016/j.ijsolstr.2016.03.004

Han, B., Xie, H. B., Zhang, D. J., \& Ma, X. (2016). Sensitivity analysis of creep models considering correlation. Materials and Structures, 49(10), 4217-4227. https://doi.org/10.1617/s11527-015-0782-4

Hedegaard, B. D., French, C. E., \& Shield, C. K. (2016). Effects of cyclic temperature on the time-dependent behavior of posttensioned concrete bridges. Journal of Structural Engineering, 142(10), 04016062. https://doi.org/10.1061/(asce)st.1943-541x.0001538

Ma, K., Xiang, T. Y., Zhao, R. D., Xu, Y., \& Xie, H. (2012). Stochastic Analysis of Long-Term Deformation of Reinforced Concrete Arch Bridge for High-Speed Railways. China Civil Engineering Journal 45(11): 141-146.

Qian, C., Zhang, Y., Huang, H., Qu, J., \& Guo, J. (2016). Influences of superplasticizers on the basic and drying creep of concrete. Structural Concrete, 17(5), 729-735. https://doi.org/10.1002/suco.201500185

Wang, Y. B., Zhao, R. D., Chen, L., Xu Y., \& Xie H.Q. (2017). Temperature Correction Test of Vibrating Wire Strain Sensor, Journal of Architecture and Civil Engineering 34(1): 68-75.

Wang, Y. F., Ma, Y. S., Han, B., \& Deng, S. Y. (2013). Temperature effect on creep behavior of CFST arch bridges. Journal of Bridge Engineering, 18(12), 1397-1405. https://doi.org/10.1061/(ASCE)BE.1943-5592.0000484 
Wang, Y., Zhan, Y., \& Zhao, R. (2016). Analysis of thermal behavior on concrete box-girder arch bridges under convection and solar radiation. Advances in Structural Engineering, 19(7), 1043-1059. https://doi.org/10.1177\%2F1369433216630829

Wendner, R., Tong, T., Strauss, A., \& Yu, Q. (2015). A case study on correlations of axial shortening and deflection with concrete creep asymptote in segmentally-erected prestressed box girders. Structure and Infrastructure Engineering, 11(12), 1672-1687. https://doi.org/10.1080/15732479.2014.992442

Xie, H.Q. (2012). Study on Structural Type Selection and Mechanical Behaviors of Long-Span Railway Concrete Arch Bridge with Rigid Skeleton (Doctoral Dissertation, Southwest Jiaotong University) (In Chinese)

Yang, M. G., Cai, C. S., \& Chen, Y. (2015). Creep performance of concrete-filled steel tubular (CFST) columns and applications to a CFST arch bridge. Steel and Composite Structures, 19(1), 111-129.

https://doi.org/10.12989/scs.2015.19.1.111

Zhang, J. (2015). A Unified Viscoelasto-Plastic Damage Model for Long-Term Performance of Prestressed Concrete Box Girders (Doctoral dissertation, University of Pittsburgh). 